\title{
Relationship between Ultrasonic Characteristics and Relative Porosity in Al and Al-XSi Alloys
}

\author{
Yeong-Jern Chen* \\ Department of Mechanical Engineering, De Lin Institute of Technology, Tu-Cheng, Taiwan 236, R. O. China
}

Pores form readily in aluminum alloy castings. The percentage of porosity is often used to quantitatively evaluate the quality of aluminum alloy castings. In this study, the relative porosity, as represented by the percentage of porosity in $\mathrm{Al}$ and $\mathrm{Al}-\mathrm{XSi}$ alloys is evaluated. Nondestructive ultrasonic techniques are adopted to investigate the relative porosity of $\mathrm{Al}$ and Al-XSi alloys. The relationship between the relative porosity and ultrasonic characteristics, including the ultrasonic velocity and the attenuation coefficient, are determined and compared, and the pore formation in the alloys is also discussed. [doi:10.2320/matertrans.M2009179]

(Received May 19, 2009; Accepted June 15, 2009; Published August 5, 2009)

Keywords: aluminum alloys, ultrasonic, relative porosity, pores

\section{Introduction}

Aluminum-silicon alloys offer the advantages of excellent castability, good corrosion resistance, and can be machined and welded. Binary eutectic or hypoeutectic aluminumsilicon alloys are characterized by good castability and corrosion resistance. ${ }^{1)}$ Hypereutectic alloys exhibit excellent wear resistance and low thermal expansion. ${ }^{2)}$ Machinability can be improved by a phosphorus treatment as the silicon particles become finer and more evenly distributed. Aluminum-silicon alloys are the materials of choice for many automotive and aerospace parts as well as domestic food and pump part castings. ${ }^{3)}$ Other applications include components for food handling and marine castings. Hydrogen is the only gas that is appreciably soluble in aluminum and its alloys. Porosity in aluminum is caused by the precipitation of hydrogen from the melt or by shrinkage during solidification, and most often by a combination of these defects. Atwood et al. ${ }^{4)}$ pointed out that the amount of hydrogen in the aluminum melt is the key factor determining the pore growth rate and its distribution in the end product after directional solidification. The pore growth rate increases as the initial hydrogen content in the melt increases and the pore size decreases as the velocity of the solid/liquid interface in the aluminum casting increases. Pores produced in aluminum-silicon alloy castings are also affected by the silicon content added to the alloy. ${ }^{5)}$ Pores that form in the matrix of aluminum alloy castings lead to significant deterioration in casting quality. In brief, porosity is formed and distributed in the matrix of the casting. The pore count of aluminum-silicon alloys can be affected by the solidification mode of the alloy, the amount of oxide film and/or particle inclusions, the cooling rate, the atmospheric pressure and the hydrogen level in the melt.

The relative porosity $(\mathrm{dc}-\mathrm{dr}) / \mathrm{dc}$, where $\mathrm{dc}$ is the density of the chilled sample and $\mathrm{dr}$ is the density of the reducedpressure sample, is used here to evaluate the quality of poured samples. ${ }^{6}$ Ultrasonic techniques are nondestructive testing methods commonly used not only to detect discontinuities such as voids, cracks and inclusions, but also used to evaluate the characteristics of a material, such as its porosity,

*Corresponding author, E-mail: jern@dlit.edu.tw microstructure, grain size and residual stress. ${ }^{7-16)}$ The ultrasonic velocity and attenuation coefficient of the ultrasound are commonly used for such purposes. Prabhakar et al. ${ }^{12,13)}$ pointed out that ultrasonic velocity increases with decreasing the porosity in $\mathrm{Al}-4.5 \% \mathrm{Cu}$ alloy castings. In addition, attenuation coefficients can be used to assess the percentage porosity in cast metals of $\mathrm{Al}-4.5 \% \mathrm{Cu}$ alloy. The attenuation coefficient increases with increasing the porosity of the castings. The velocity of an ultrasonic wave as it propagates through a solid material is affected by the elastic modulus $(E)$, the density $(\rho)$, and the Poisson's ratio $(\mu)$. The relationships among these properties and the longitudinal velocity of the ultrasound $\left(V_{\mathrm{L}}\right)$ can be expressed as follows: ${ }^{17)}$

$$
V_{\mathrm{L}}=\sqrt{\frac{E(1-\mu)}{\rho(1+\mu)(1-2 \mu)}} .
$$

When an ultrasonic wave travels through a solid, its amplitude $(A)$ or its intensity $(I)$ will decay exponentially with respect to the distance $(X)$ of the sound propagation ${ }^{8)}$

$$
A=A_{0} \exp (-\alpha X) \text { or } I=I_{0} \exp (-\alpha X),
$$

where $A_{0}$ and $I_{0}$ are the initial amplitude and the initial intensity of the ultrasound, respectively. The attenuation coefficient $(\alpha)$ can be described by ${ }^{17)}$

$$
\alpha(f)=\frac{20\left[\log \left(\frac{A_{1}}{A_{2}}\right)+2 \log R\right]}{2 X},
$$

where $\alpha(f)$ is the attenuation coefficient of the ultrasound, which varies with frequency $(\mathrm{dB} / \mathrm{mm}) ; A_{1}$ and $A_{2}$ are peak amplitudes of the first and second transmitted pulses $(\mathrm{dB})$; and $X$ is the thickness of the sample $(\mathrm{mm})$. The term $R$, the reflection coefficient of the coupling plane, is equal to $[(1-\eta) /(1+\eta)]^{2}$, and $\eta$ is the acoustic impedance of the coupling plane; $\eta=Z_{1} / Z_{2}$, and $Z_{1}, Z_{2}$ are the acoustic impedance of the first and second medium, respectively. The attenuation coefficient of the ultrasound is affected by the absorption and the scattering. The absorption is influenced by dislocation damping, magnetic resistance, and the thermal elasticity of the materials. The scattering is influenced by the grain boundaries, voids, inclusions, second phase particles, cracks, etc. ${ }^{12)}$ 
It is important to understand the effect of pores on the quality of aluminum alloy castings. Nondestructive ultrasonic techniques were applied to evaluate the porosity of the alloys. In particular we focused on the relationship between ultrasonic characteristics and relative porosity in $\mathrm{Al}$ and $\mathrm{Al}$-XSi alloys. The relative porosity was used to assess the quality of aluminum alloy castings. The formation of pores in the alloys is also discussed.

\section{Experimental Procedures}

An induction furnace equipped with a $\mathrm{SiC}$-graphite-clay crucible was used to melt $20-25 \mathrm{~kg}$ batches of aluminum alloy. A master alloy of Al-50 mass \% Si was added to the melt in order to bring the silicon content to the desired levels. Different batches of pure aluminum (99.86 mass\%), Al6 mass $\% \mathrm{Si}$ and Al-13 mass $\% \mathrm{Si}$ were sequentially degassed by nitrogen gas using a lance diffuser for $1800 \mathrm{~s}$. The $50 \mathrm{~mm}$ lance was porous and made of graphite. After the degassing treatment, the molten metal was held at $700^{\circ} \mathrm{C}$ for $600 \mathrm{~s}$. The hydrogen content of the molten metal was then tested using a BOMEN ALSCAN at $700^{\circ} \mathrm{C}$. The molten metal was poured into a spoon made of ceramic fiber, and then poured to make chilled and reduced-pressure samples. A residual pressure of $76 \mathrm{mmHg}$ was employed for marking the reduced-pressure samples. The constituents of the samples were analyzed by spectrometer; see Table 1 . The chilled samples were polished again. The pore counts were then measured using an optical microscope equipped with an image analyzer. Each sample was measured ten times and the average of the total pore counts was obtained.

The density of the samples was measured by Archimedes' method. The chilled samples had a rapid solidification rate of about $4.5^{\circ} \mathrm{C} / \mathrm{s}$. The reduced-pressure samples solidified under the condition of reduced pressure and had a relatively low cooling rate of about $0.3^{\circ} \mathrm{C} / \mathrm{s}$, which promoted the growth and coalescence of pores. Differences in the densities and the pore morphologies were influenced by the different cooling rates and the reduced pressure. The top and bottom surface of the chilled sample were machined to produce two parallel planes. An ultrasonic A-scan instrument was used for ultrasonic evaluation of the longitudinal ultrasonic velocity and the attenuation coefficient of the chilled samples. The ultrasonic velocity $(v)$ was calculated by observing the time $(t)$ difference between two back-reflected pulses and the specimen thickness $(d), v=2 d / t$. The attenuation coefficient was determined by examining the peak amplitudes of the first and the second pulses peak, amplitudes $A_{1}$ and $A_{2}$ in eq. 3 . An ultrasonic straight-beam probe, $10 \mathrm{~mm}$ in diameter, was used at frequencies of $5 \mathrm{MHz}$ and $10 \mathrm{MHz}$ for the testing. Commercial motor oil was adopted as the coupling agent

Table 1 Chemical composition of pure $\mathrm{Al}$ and $\mathrm{Al}-\mathrm{XSi}$ alloys.

\begin{tabular}{crcc}
\hline \multirow{2}{*}{ Materials } & \multicolumn{3}{c}{ Main element (mass\%) } \\
\cline { 2 - 4 } & \multicolumn{1}{c}{$\mathrm{Si}$} & $\mathrm{Fe}$ & $\mathrm{Al}$ \\
\hline Pure aluminum & 0.08 & 0.11 & balance \\
Al-6 mass\%Si & 6.06 & 0.14 & balance \\
Al-13 mass\%Si & 13.29 & 0.18 & balance \\
\hline
\end{tabular}

for the ultrasonic contact-type testing in these experiments. Five ultrasonic readings were taken for each specimen. One measurement position is located at the center of specimen. Four measurement positions are divided equally from the circumference of specimen. The average value of ultrasonic readings represented in the obtained data.

\section{Results and Discussion}

\subsection{Microstructure of Al and Al-XSi alloys}

The microstructure of the chilled sample of aluminum and Al-XSi alloys is shown in Figs. 1(a)-(c). The microstructure of pure aluminum shows equiaxed grains of aluminum (see Fig. 1(a)). The eutectic composition is close to 12 mass $\% \mathrm{Si}$. In the Al-6 mass\%Si alloy (hypoeutectic alloy), aluminum precipitates from the melt appear in the primary phase in the form of dendrites. The results of optical microscopy reveal the presence of $\alpha$-Al dendrites and the eutectic silicon phase, (see Fig. 1(b)). In the Al-13 mass\%Si alloy (hypereutectic alloy), star-shaped primary silicon particles are formed in the melt upon cooling. The microstructure of hypereutectic Al13 mass $\% \mathrm{Si}$ alloys is commonly composed of primary silicon particles and a eutectic structure of $\alpha$-Al and $\mathrm{Si}$ (see Fig. 1(c)). The high strength and wear resistance of these alloys can be attributed to the presence of hard silicon particles.

The chilled samples were polished and optical observations carried out to obtain the pore count, as seen in Table 2. The pure aluminum samples have the lowest pore count among all the samples. The Al-13 mass\%Si alloy has a lower pore count than the Al-6 mass\%Si alloy. Inclusion particles and oxide films provide nucleation sites for the pore. Pores in the sample are thus normally accompanied by inclusion particles or oxide films. Figure 2 shows inclusion particles and oxide films trapped in pores on the fractured surface of an Al-6 mass\%Si alloy reduced-pressure sample. It is possible that the individual pores could coalesce to form more substantial gas pores. Almost no gas pores exist in the pure aluminum samples, either the chilled or the reduced-pressure samples. In the Al-XSi alloys, there are significant pores in both the chilled and reduced-pressure samples. The size of the pores is affected by the hydrogen content and solidification rate. Generally, the pore growth rate increases as the hydrogen content increases and the solidification rate decreases.

\subsection{Relationship between hydrogen content and relative porosity}

The experimental data for $\mathrm{Al}$ and $\mathrm{Al}-\mathrm{XSi}$ alloys with various hydrogen content levels are shown in Table 2. The relative porosity of aluminum alloys is greatly affected by the solidification mode and hydrogen content in the melt. Figure 3 shows the effect of hydrogen content on the relative porosity of the different alloys. When the relative porosity is small, there are no visible pores in the sample or only a minor amount of micro porosity. Increasing the silicon content decreases the hydrogen absorbed in the Al-XSi melt. A comparison of pure $\mathrm{Al}$ and $\mathrm{Al}-\mathrm{XSi}$ alloys shows that the Al$\mathrm{XSi}$ alloys had a relative porosity more than 10 times that of pure aluminum even when the hydrogen content was lower. 
(a)

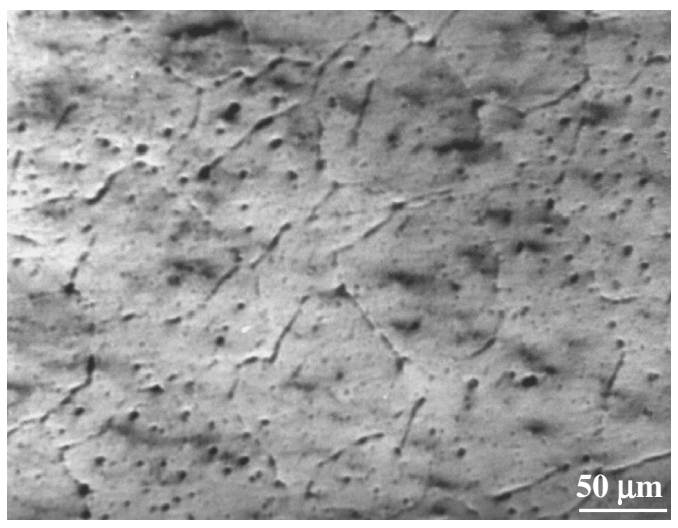

(b)

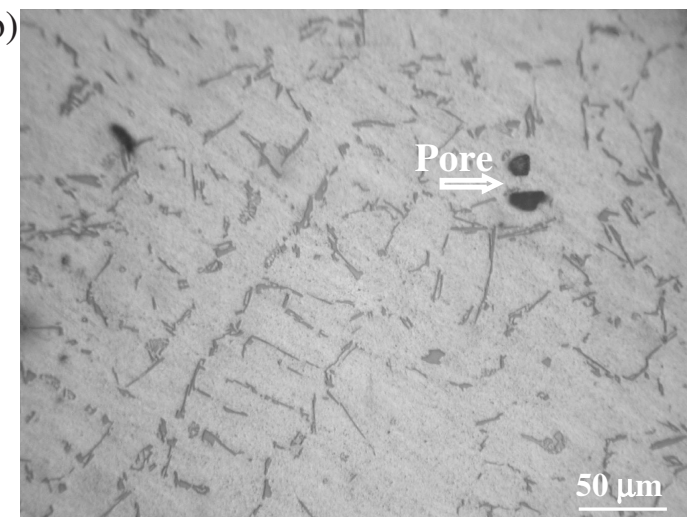

(c)

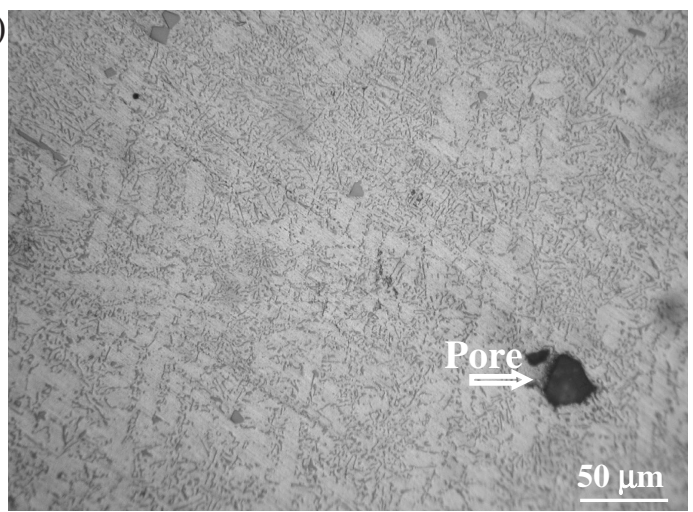

Fig. 1 The microstructure of pure Al and Al-XSi alloys: (a) pure Al; (b) Al-6 mass\%Si alloy; (c) Al-13 mass\%Si.

Table 2 Experimental data for pure $\mathrm{Al}$ and $\mathrm{Al}-\mathrm{XSi}$ alloys.

\begin{tabular}{|c|c|c|c|c|c|c|c|c|c|}
\hline \multirow[t]{2}{*}{ Materials } & \multirow{2}{*}{$\begin{array}{c}\text { Density } \\
\text { of } \\
\text { chilled } \\
\text { sample } \\
\left(\mathrm{g} / \mathrm{cm}^{3}\right)\end{array}$} & \multirow{2}{*}{$\begin{array}{l}\text { Density } \\
\text { of } \\
\text { reduced } \\
\text {-pressure } \\
\text { sample } \\
\left(\mathrm{g} / \mathrm{cm}^{3}\right)\end{array}$} & \multirow{2}{*}{$\begin{array}{c}\text { Relative } \\
\text { porosity } \\
(\%)\end{array}$} & \multirow{2}{*}{$\begin{array}{c}\text { Hydrogen } \\
\text { content } \\
\left(\mathrm{cm}^{3} / 100 \mathrm{~g} \mathrm{Al}\right)\end{array}$} & \multirow{2}{*}{$\begin{array}{c}\text { Pore } \\
\text { count } \\
\text { (counts } / \mathrm{mm}^{2} \text { ) }\end{array}$} & \multicolumn{2}{|c|}{$\begin{array}{l}\text { Ultrasonic velocity } \\
\qquad(\mathrm{m} / \mathrm{s})\end{array}$} & \multicolumn{2}{|c|}{$\begin{array}{l}\text { Attenuation coefficient } \\
\qquad(\mathrm{dB} / \mathrm{mm})\end{array}$} \\
\hline & & & & & & $f=5 \mathrm{MHz}$ & $f=10 \mathrm{MHz}$ & $f=5 \mathrm{MHz}$ & $f=10 \mathrm{MHz}$ \\
\hline \multirow{4}{*}{ Pure Al } & 2.707 & 2.700 & 0.27 & 0.170 & \multirow{4}{*}{36} & 6450 & 6440 & 0.14 & 0.196 \\
\hline & 2.706 & 2.700 & 0.22 & 0.226 & & 6436 & 6421 & 0.146 & 0.211 \\
\hline & 2.705 & 2.704 & 0.05 & 0.251 & & 6429 & 6424 & 0.154 & 0.229 \\
\hline & 2.707 & 2.702 & 0.19 & 0.312 & & 6411 & 6380 & 0.165 & 0.240 \\
\hline \multirow{4}{*}{$\begin{array}{c}\text { Al-6 mass } \\
\% \mathrm{Si}\end{array}$} & 2.689 & 2.648 & 1.52 & 0.119 & \multirow{4}{*}{106} & 6588 & 6563 & 0.181 & 0.235 \\
\hline & 2.683 & 2.621 & 2.30 & 0.123 & & 6537 & 6546 & 0.19 & 0.275 \\
\hline & 2.686 & 2.615 & 2.66 & 0.156 & & 6531 & 6516 & 0.207 & 0.280 \\
\hline & 2.687 & 2.538 & 5.54 & 0.204 & & 6496 & 6450 & 0.253 & 0.380 \\
\hline \multirow{4}{*}{$\begin{array}{c}\mathrm{Al}-13 \text { mass } \\
\% \mathrm{Si}\end{array}$} & 2.649 & 2.634 & 0.57 & 0.087 & \multirow{4}{*}{74} & 6716 & 6712 & 0.173 & 0.190 \\
\hline & 2.652 & 2.630 & 0.80 & 0.091 & & 6697 & 6692 & 0.179 & 0.204 \\
\hline & 2.646 & 2.619 & 1.02 & 0.138 & & 6693 & 6686 & 0.181 & 0.207 \\
\hline & 2.642 & 2.566 & 2.88 & 0.172 & & 6679 & 6668 & 0.207 & 0.283 \\
\hline
\end{tabular}

When the hydrogen content in the alloys was low, the relative porosity was small and slightly varied. In other words, the effect of silicon on the relative porosity was minor. The relative porosity was substantially scattered in all samples when the hydrogen content was high.

The relative porosity was lowest in the pure aluminum samples. The Al- 6 mass $\%$ Si alloy possessed the highest relative porosity. The relationship between hydrogen content and relative porosity showed a similar trend to that of the Al-
6 mass $\% \mathrm{Si}$ and $\mathrm{Al}-13$ mass $\% \mathrm{Si}$ alloys. For any given hydrogen content, the Al-6 mass\%Si alloys had a slightly greater relative porosity than the Al-13 mass\%Si alloys. The shapes of the pores mainly depend on the solidification rate, the morphology of the particle surface and the hydrogen content. There are almost no pores displayed in the sectioned pure $\mathrm{Al}$ reduced-pressure sample; see Figs. 4(a) and 4(b). The Al6 mass \%Si alloy shows numerous pores dispersed throughout the sectioned reduced-pressure sample, as shown in Fig. 4(c). 
(a)

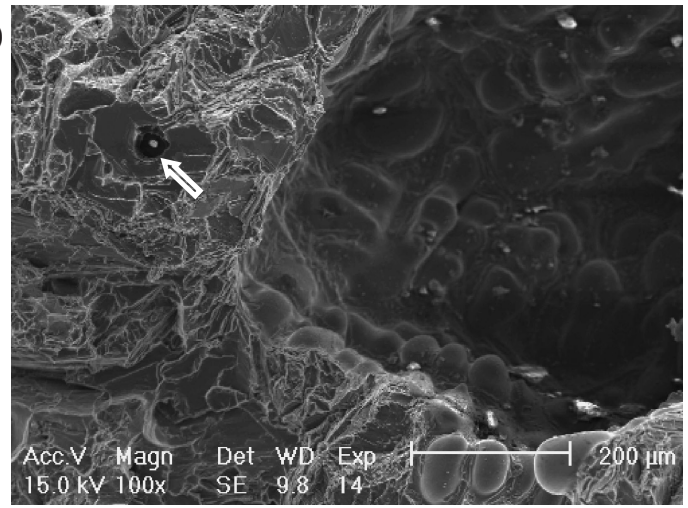

\begin{tabular}{rrrlllll}
\hline \multicolumn{7}{c}{ EDS analysis } \\
Element & Wt \% & \multicolumn{1}{c}{ At \% } & K-Ratio & Z & A & F \\
\hline O K & 11.60 & 18.22 & 0.0421 & 1.0666 & 0.3395 & 1.0011 \\
NaK & 0.84 & 0.92 & 0.0065 & 0.9951 & 0.7625 & 1.0160 \\
AlK & 76.47 & 71.22 & 0.7132 & 0.9879 & 0.9421 & 1.0021 \\
SiK & 9.80 & 8.77 & 0.0513 & 1.0138 & 0.5160 & 1.0001 \\
C1K & 0.51 & 0.36 & 0.0038 & 0.9586 & 0.7739 & 1.0003 \\
K K & 0.78 & 0.50 & 0.0066 & 0.9614 & 0.8837 & 1.0000 \\
Total & 100.00 & 100.00 & & & & \\
\hline
\end{tabular}

(b)

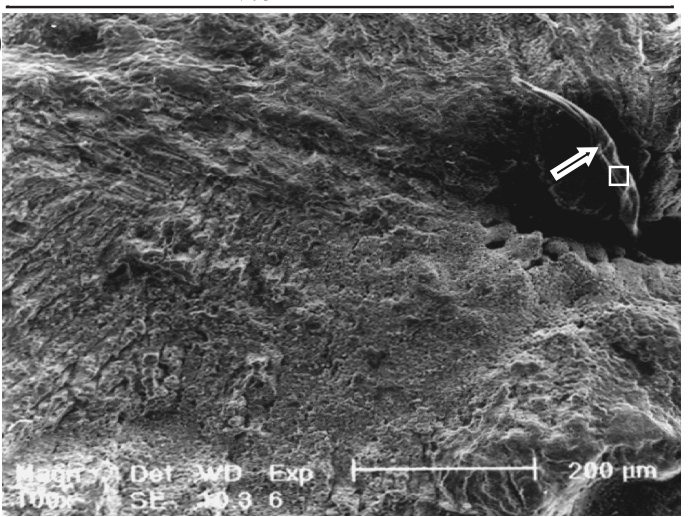

Fig. 2 Inclusion particles and oxide films with pores on the fractured surface of a Al-6 mass\%Si reduced-pressure specimen: (a) inclusion particle with pore; (b) oxide film with pore.

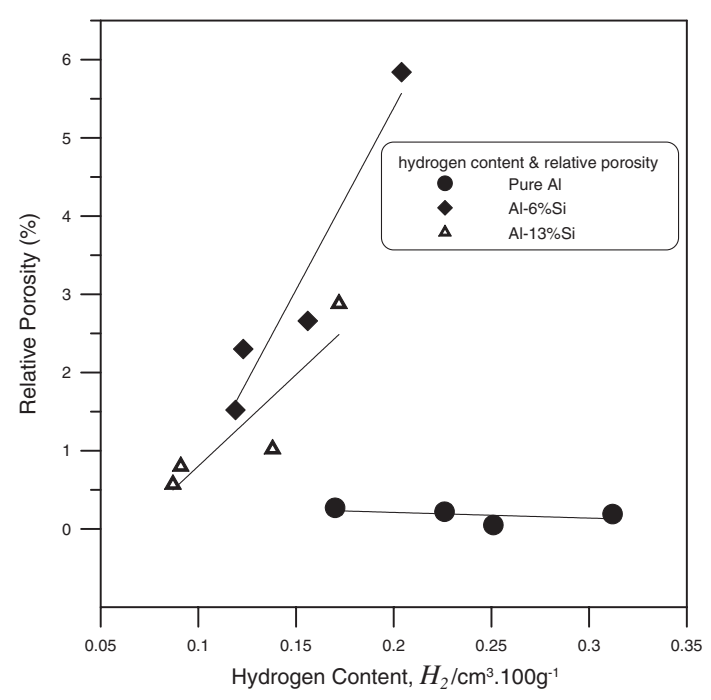

Fig. 3 Relationship between relative porosity and hydrogen content measured in the melts of pure $\mathrm{Al}, \mathrm{Al}-6$ mass $\% \mathrm{Si}$ and $\mathrm{Al}-13$ mass $\% \mathrm{Si}$.
Eutectic solidification in the Al-13 mass\%Si alloy released a great amount of latent heat. This would cause pores solidified to form small sizes in the reduced-pressure sample, as shown in Fig. 4(d).

\subsection{Reflection and transmission of ultrasound at the interface of $\mathrm{Al} / \mathrm{Si}$ and $\mathrm{Al} /$ pore}

Acoustic impedance shows the resistance of a material to the passage of sound waves. The acoustic impedance $(Z)$ of a material is defined as the product of its density $(\rho)$ and the ultrasonic velocity $(V), Z=\rho \times V$. Ultrasonic waves are reflected at boundaries where there are differences in the acoustic impedance of the materials on either side of the boundary. The greater the impedance mismatch, the greater the percentage of energy that will be reflected at the interface or boundary between one medium and another. The reflection coefficient $(R)$ and transmission coefficient $(D)$ of the ultrasound at the interface of two mediums can be calculated with eqs. (4)-(6) ${ }^{17)}$ (a)

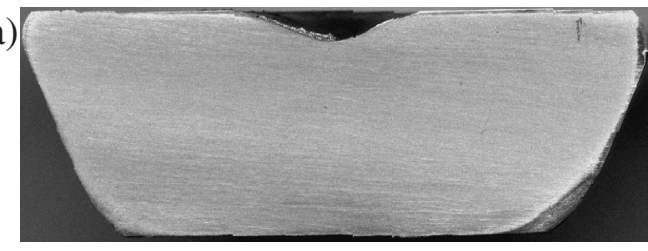

(b)

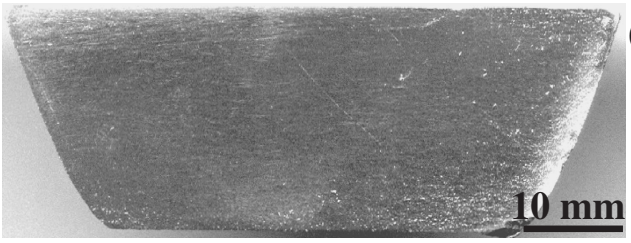

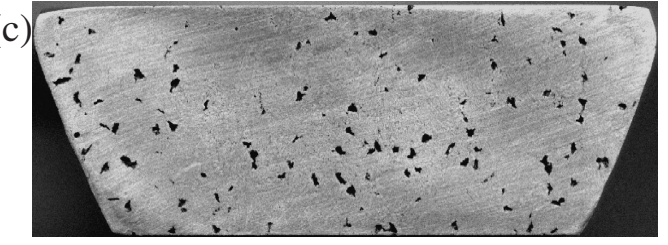

(d)

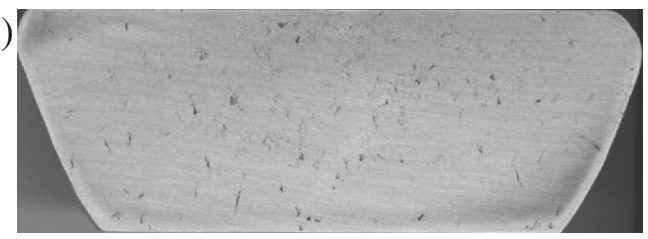

Fig. 4 Optical micrographs indicating pores in the sections of the reduced pressure test samples from different melts and hydrogen levels: (a) pure $\mathrm{Al}$ with hydrogen level of $0.226\left(\mathrm{~cm}^{3} / 100 \mathrm{~g} \mathrm{Al}\right)$; (b) pure $\mathrm{Al}$ with hydrogen level of $0.312\left(\mathrm{~cm}^{3} / 100 \mathrm{~g} \mathrm{Al}\right) ;$ (c) Al-6 mass $\% \mathrm{Si}$ with hydrogen level of $0.204\left(\mathrm{~cm}^{3} / 100 \mathrm{~g} \mathrm{Al}\right)$; (d) Al-13 mass\%Si with hydrogen level of $0.172\left(\mathrm{~cm}^{3} / 100 \mathrm{~g} \mathrm{Al}\right)$. 


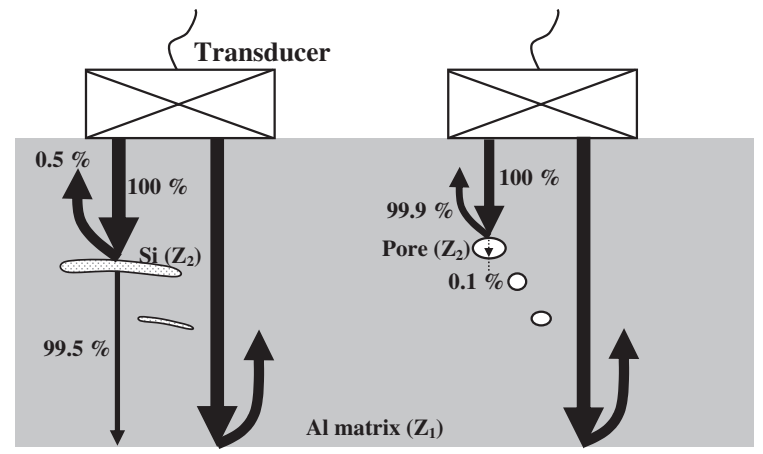

Fig. 5 Schematic illustration of transmission and reflection of the ultrasound at the interface between the $\mathrm{Al} / \mathrm{Si}$ and $\mathrm{Al} /$ pores.

$$
\begin{aligned}
& R=\left(\frac{Z_{2}-Z_{1}}{Z_{2}+Z_{1}}\right)^{2}, \\
& D=\frac{4 Z_{1} Z_{2}}{\left(Z_{2}+Z_{1}\right)^{2}}, \\
& R+D=1 .
\end{aligned}
$$

The reflection coefficient can be defined either in terms of energy (intensity) or amplitude (pressure). Multiplying the reflection coefficient by 100 yields the reflection energy $(R E)$ as a percentage of the original ultrasonic energy. The total amount of ultrasonic energy $(100 \%)$ equals the amount of reflection energy plus the transmission energy $(D E)$, i.e., $R E+D E=100 \%$. The acoustic impedances of elemental $\mathrm{Al}$ and $\mathrm{Si}$ are $17.06 \times 10^{6}$ and $19.64 \times 10^{6} \mathrm{~kg} / \mathrm{m}^{2} \cdot \mathrm{s}$, respectively. The reflection energy and transmission energy of the ultrasound at the aluminum/silicon interface are about $0.5 \%$ and $99.5 \%$, respectively. The energy loss of the ultrasound as it passes through the interface is only a small percentage $(0.5 \%)$ of the original energy, therefore ultrasonic attenuation can be ignored. The interface between the pore and the aluminum matrix can be taken as the boundary between the solid and air. The acoustic impedance of air is about $3.3 \times 10^{2} \mathrm{~kg} / \mathrm{m}^{2} \cdot \mathrm{s}$. When an ultrasonic wave pass through the pore, they tend to be fully reflected at the boundary between the aluminum and the pore. The reflection energy of the ultrasound is estimated to be as high as $99.9 \%$, therefore the effect of pores on ultrasonic attenuation is a key factor. A schematic illustration of transmission and reflection at the interface between the two mediums is shown in Fig. 5.

\subsection{Ultrasonic characteristics of $\mathrm{Al}$ and $\mathrm{Al}-\mathrm{XSi}$ alloys}

Numerous pores exist in the sectioned reduced-pressure specimen. There is a serious loss of ultrasonic energy due to the sound scattering and reflection that occurs at the interface between the pores and the substrate, therefore the bottom echo pulse cannot be reflected to the ultrasonic receiver during the testing procedure. Thus the ultrasonic evaluation method cannot be used to measure the ultrasonic velocity or the attenuation coefficient in the reduced-pressure samples. The chilled sample has mainly minor micro-pores that caused only a slight reduction in the sound energy of the ultrasound. Therefore, the ultrasonic testing method can be used to detect the characteristics of $\mathrm{Al}$ and $\mathrm{Al}-\mathrm{XSi}$ alloys.

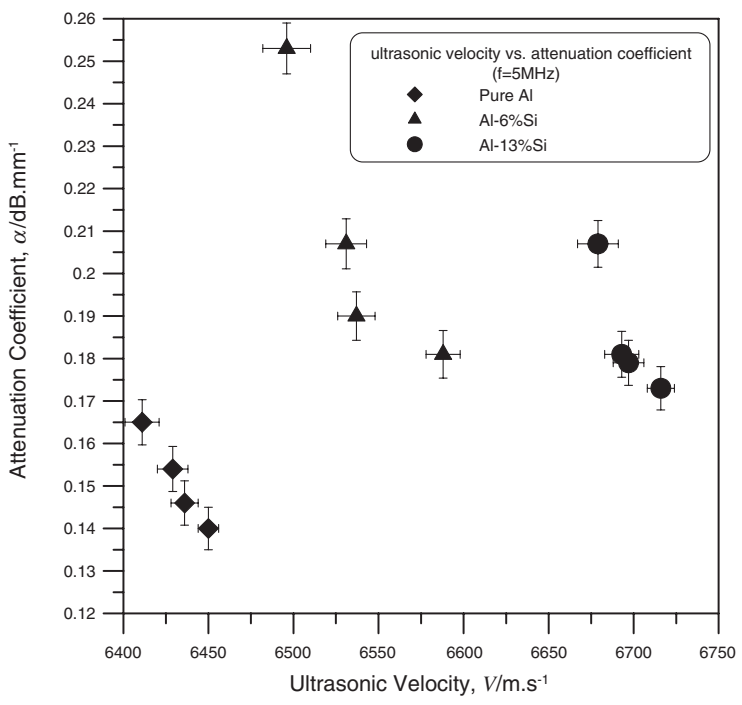

Fig. 6 Relationship between ultrasonic velocity and attenuation coefficient in pure $\mathrm{Al}$ and $\mathrm{Al}-\mathrm{XSi}$ alloys.

The values of the ultrasonic velocity and attenuation coefficients of the chilled $\mathrm{Al}$ and $\mathrm{Al}-\mathrm{XSi}$ alloy samples are listed in Table 2. Figure 6 shows the relationship between ultrasonic velocity and attenuation coefficient for chilled $\mathrm{Al}$ and Al-XSi alloy samples. The attenuation coefficient decreases with increasing ultrasonic velocity for all the samples. The magnitudes of the ultrasonic velocity are in the following order: pure $\mathrm{Al}, \mathrm{Al}-6$ mass $\% \mathrm{Si}$ alloy and Al-13 mass\%Si alloy, and increase as the silicon content increases. The ultrasonic velocity is about $8433 \mathrm{~m} / \mathrm{s}$ and $6320 \mathrm{~m} / \mathrm{s}$ for elemental $\mathrm{Si}$ and $\mathrm{Al}$, respectively. ${ }^{17)}$ The ultrasonic velocity is far larger for silicon than for aluminum. The silicon phase in the alloy promotes the sound velocity. There is most silicon in the matrix of the Al-13 mass $\% \mathrm{Si}$ alloy (compared with the pure Al and Al-6 mass\%Si alloy), thus it has the largest ultrasonic velocity. The attenuation coefficient is smallest for pure Al because it does not have nearly the number of pores as the other alloys. On the other hand, there are many pores dispersed throughout the matrix of the Al-6 mass\%Si alloy, which encouraged the scattering of sound and energy loss of ultrasound propagation in the sample. Therefore, the attenuation coefficient of the Al6 mass \% Si alloy sample was larger.

Figure 7 shows the relationship between the ultrasonic velocity and relative porosity in pure $\mathrm{Al}$ and $\mathrm{Al}-\mathrm{XSi}$ alloys. The relative porosity of pure aluminum is small. There are no visible pores in the pure $\mathrm{Al}$ sample. There are only very small variations in the ultrasonic velocity for the chilled pure aluminum sample. For the Al-6 mass\%Si and Al-13 mass\%Si alloy samples, the ultrasonic velocity decreases as the relative porosity increases. This is due to a decrease of the effective elastic stiffness of the alloys with increasing pore content. There was obvious scattering in the variations of the ultrasonic velocity for the Al-6 mass\%Si sample due to the presence of micro-pores in the paths of the ultrasonic waves which promoted boundary scattering and energy loss in the ultrasound. In general, no apparent sound velocity differences between the various testing frequencies for uniform materials. ${ }^{14)}$ For Al-XSi alloys, at any given relative porosity, 


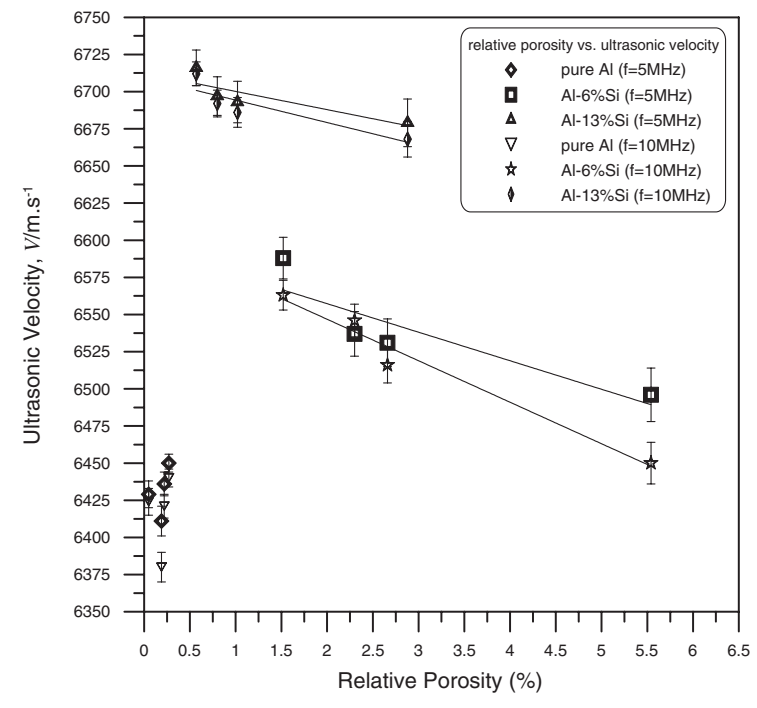

Fig. 7 Relationship between relative porosity and ultrasonic velocity in pure $\mathrm{Al}$ and $\mathrm{Al}-\mathrm{XSi}$ alloys.

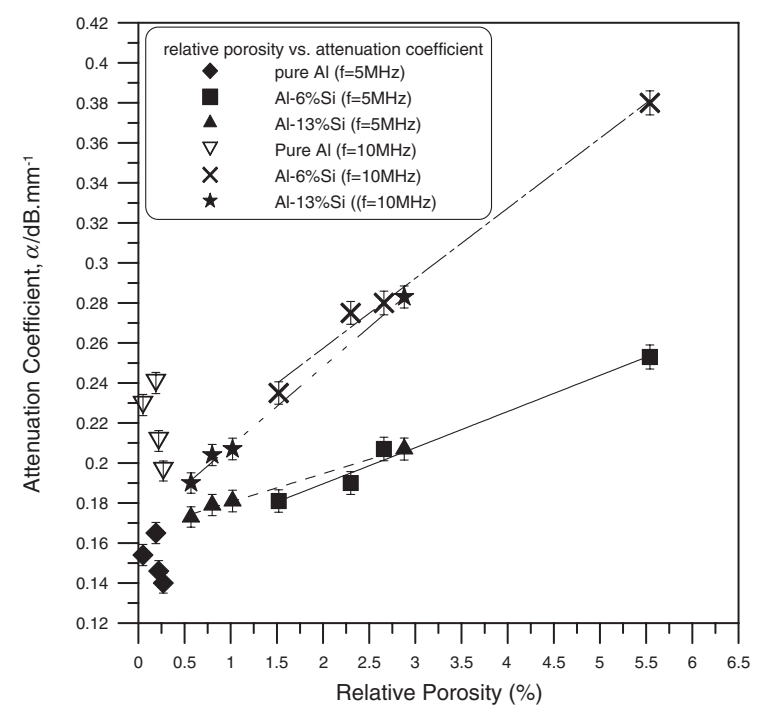

Fig. 8 Relationship between relative porosity and attenuation coefficient in pure Al and Al-XSi alloys.

ultrasonic velocity at $5 \mathrm{MHz}$ appeared to be higher than that of the $10 \mathrm{MHz}$. The reason of this was a higher ultrasonic frequency with the smaller wavelength resulted in greater interference when an ultrasound passes through the pores. Figure 8 shows the relationship between the attenuation coefficient and relative porosity in pure $\mathrm{Al}$ and $\mathrm{Al}-\mathrm{XSi}$ alloys. Similarly, it can be observed that variations in the attenuation coefficients are really small in pure aluminum samples due to the minor amount of microporosity. The attenuation coefficient of the Al-XSi alloy samples increases with increasing relative porosity. The largest attenuation among the alloys studied is shown for the Al-6 mass\%Si alloy. In addition, a higher ultrasonic frequency leads to a higher attenuation coefficient. The smaller wavelength at higher ultrasonic frequencies resulted in greater scattering of ultrasound propagation along the sound paths, therefore the attenuation coefficient variations were more pronounced.

\section{Conclusions}

The presence of pores leads to a serious reduction in the quality of aluminum and aluminum alloys. The relative porosity can be used to quantitatively evaluate the formation of pores in aluminum and aluminum alloys. The relative porosity is low and slightly different values in all the alloys with a low hydrogen content. The relative porosity increases with increasing hydrogen content. The lowest relative porosity was observed in pure aluminum. The Al-6 mass\% $\% \mathrm{Si}$ alloy had the highest relative porosity among the alloys. The Al-13 mass\%Si alloy had a slightly smaller relative porosity than did the Al-6mass\%Si alloy. Increasing the silicon content in the sample induces the formation of pores.

Ultrasonic inspection can be used to evaluate the relative porosity of the alloys. Variations of the ultrasonic velocity and attenuation coefficient in the chilled pure aluminum sample are really small. In Al-XSi alloys the ultrasonic velocity decreases with increasing the relative porosity. The attenuation coefficient of the Al-XSi alloy samples increases with increasing relative porosity. The attenuation coefficient of the Al-6 mass\%Si alloy was the largest among the alloys studied.

\section{Acknowledgements}

The author would like to thank the National Science Council of Taiwan, ROC, for their financial support of this project under grant number NSC 96-2622-E-237-007-CC3.

\section{REFERENCES}

1) S. Shankar, Y. W. Riddle and M. M. Makhlouf: Acta Mater. 52 (2004) 4447-4460.

2) D. Lu, Y. Jiang, G. Guan, R. Zhou, Z. Li and R. Zhou: J. Mater. Process. Technol. 189 (2007) 13-18.

3) M. Gupta and S. Ling: J. Alloy. Compd. 287 (1999) 284-294.

4) R. C. Atwood, S. Sridhar, W. Zhang and P. D. Lee: Acta Mater. 48 (2000) 405-417.

5) J. M. Kim, H. W. Kwon and C. R. Loper, Jr.: AFS Trans. 104 (1996) 743-749.

6) T. S. Shih, L. W. Huang and Y. J. Chen: Int. J. Cast. Metals Res. 18 (2005) 301-308.

7) L. Adler, J. H. Rose and C. Mobley: J. Appl. Phys. 59 (1986) 336-347.

8) A. D. Degtyar, A. I. Lavrentyev and S. I. Rokhlin: Mater. Eval. 55 (1997) 1162-1168

9) C. H. Hsu, H. Y. Teng and S. C. Chiu: Mater. Trans. 44 (2003) 23632368.

10) C. H. Hsu, H. Y. Teng and Y. J. Chen: J. Mater. Eng. Perform. 13 (2004) 593-599.

11) J. C. Gonzalez, L. M. Sanchez and J. N. Alcocer: Mater. Des. 16 (1995) 47-50.

12) O. Prabhakar, R. Ambardar and H. K. Wah: Insight 39 (1997) 100103.

13) R. Ambardar, T. Jayakumar, S. D. Pathak and O. Prabhakar: Insight 38 (1996) 502-508.

14) L. S. Chang, T. H. Chuang and W. J. Wei: Mater. Charact. 45 (2000) 221-226.

15) J. Xu, J. Zhang, Y. DU, X. Zhang and Y. Li: Mater. Lett. 29 (1996) 131-134.

16) H. Jeong and D. K. Hsu: Ultrasonics 33 (1995) 195-203.

17) P. Mclntire: Nondestructive Testing Handbook, Ultrasonic Testing, 7 (ASNT, USA, 1991) pp. 384-409. 